\title{
0 Tema Meio Ambiente e sua inserção em duas coleções de livros didáticos de Matemática para os anos finais do Ensino Fundamental
}

Karine Machado Fraga de Melo

Claudia Lisete Oliveira Groenwald

\section{Resumo}

Este artigo apresenta a análise de como o tema transversal Meio Ambiente está sendo abordado em duas coleções de livros didáticos de Matemática para os anos finais do Ensino Fundamental, bem como, sua adequação aos Parâmetros Curriculares Nacionais (PCN). O objetivo desta pesquisa foi investigar como o tema transversal Meio Ambiente é explorado nos livros didáticos de Matemática e se colaboram para uma educação mais crítica acerca dos conhecimentos matemáticos. Foram pesquisadas duas coleções de Matemática, adotadas por escolas estaduais de Porto Alegre, no Estado do RS. Os resultados evidenciam que a abordagem do tema transversal Meio Ambiente está presente nos livros didáticos de Matemática, em sintonia com a proposta sugerida nos PCN, adotando uma concepção crítica e contextualizadora do conhecimento matemático, a qual propicia ao educando tanto a aquisição do conceito das técnicas e algoritmos quanto estimula a discussão e a percepção do contexto social.

Palavras-chave: educação matemática, livro didático de matemática, meio ambiente.

\footnotetext{
Abstract

Theme Environment and its insertion into two collections of Mathematics textbooks for the final years of elementary school

This article presents an analysis of how a transversal theme like environment is approached in two collections of Math didactic books for last four years of Elementary School, as well as, their adjustment to National Curriculum Parameters (NCP). The main purpose of this research was to investigate how the traversal theme environment is explored in the Math books e cooperate to more critical education about mathematical knowledge. Two Math book collections were used in the research, which were adopted by two state schools in Porto Alegre, in Rio Grande do Sul. The results have showed that an approach of environment is presented in the books, by following the NCP and having a critical and contextualized conception of Math knowledge that can provide to students either acquisition of technical concepts and algorithm or discussion and
} 
perception of social context.

Key-words: mathematical education, math didactic book, environment.

\section{Introdução}

Nas escolas públicas brasileiras, o livro didático é distribuído pelo Ministério de Educação (MEC) em parceria com o Fundo Nacional de Desenvolvimento da Educação (FNDE). Além disso, há uma política de incentivo à adoção do livro didático que é reafirmada pelo Programa Nacional do Livro Didático (PNLD), o qual declara que nas escolas brasileiras esse tipo de publicação constitui-se como uma das principais ferramentas pedagógicas no processo de ensino e aprendizagem.

Nesse sentido, o livro didático é um produto destinado às escolas como uma das fontes orientadoras ao processo de ensino e aprendizagem do educador, ao estudo do educando. De acordo com o Guia de Livros Didáticos do PNDL, "o livro didático contribui para o processo de ensino e aprendizagem como um interlocutor que dialoga com o professor e com o aluno" (BRASIL, 2010). O livro didático é um meio pelo qual o professor, interagindo com seus alunos, pode discutir as aplicações que a Matemática oferece na vida do cidadão, agregando aspectos importantes como o compromisso com o meio ambiente. Por isso, é pertinente investigar como essa ferramenta pedagógica utilizada para o ensino de Matemática contribui para a formação do cidadão com a perspectiva apresentada nos Parâmetros Curriculares Nacionais (PCN).

"Há necessidade de uma proposta de educação matemática que se torne formadora de hábitos, atitudes e comportamentos que devem identificar problemas, formular propostas e atuar no sentido da preservação do meio ambiente, bem como, desenvolver e aprofundar os conteúdos de Matemática, com compreensão e com uma visão crítica, formadora da cidadania" (FILIPPSEN; GROENWALD, 2003, p.1).

Uma proposta relevante ao processo de ensino e aprendizagem de Matemática, que hoje permeia os PCN, é a busca por articular temas transversais e a concepção de interdisciplinaridade. Neste trabalho, procurou-se investigar como é a relação entre a abordagem do tema transversal Meio Ambiente e o conteúdo matemático apresentado no livro didático.

\section{O Programa Nacional do Livro Didático - PNLD/2011}

Para prover as escolas públicas de Ensino Fundamental e Médio com livros didáticos, dicionários e obras complementares de qualidade, o governo federal executa o PNLD. O Programa é executado em ciclos trienais alternados. Assim, a cada ano o FNDE adquire e distribui livros para 
todos os alunos de um segmento, que pode ser: anos iniciais do Ensino Fundamental, anos finais do Ensino Fundamental ou Ensino Médio. À exceção dos livros consumíveis, os livros distribuídos deverão ser conservados e devolvidos para utilização por outros alunos nos anos subsequentes.

Cada escola escolhe democraticamente, dentre os livros constantes no Guia do PNLD, aquele que deseja utilizar, levando em consideração seu planejamento pedagógico.

Para serem enviados às escolas públicas, os livros didáticos passam por um processo avaliativo organizado pelo MEC em parceria com o FNDE. O MEC inclui o aperfeiçoamento de suas propostas a partir de critérios qualitativos e eliminatórios, uma avaliação dos livros inscritos no PNLD e, ainda, a elaboração de um guia com resenhas que auxiliem os educadores na hora da escolha.

O PNLD é o mais antigo dos programas voltados à distribuição de obras didáticas aos estudantes da rede pública do ensino brasileiro e iniciou-se, com outra denominação, o Instituto Nacional do Livro (INL), em 1929. Ao longo desses quase 70 anos, o programa tem representado um importante instrumento de apoio ao processo de ensino e aprendizagem, ajustando-se, continuamente, às mudanças e às novas demandas colocadas para atendimento aos objetivos tanto do Ensino Fundamental como do Ensino Médio. É uma iniciativa do MEC e tem a função de adquirir obras didáticas de qualidade e, por intermédio do FNDE, distribuí-las às escolas públicas cadastradas no Censo Escolar. Essa distribuição é feita diretamente das editoras às escolas públicas, por meio do FNDE e da Empresa Brasileira de Correios e Telégrafos (ECT).

\section{Educação Matemática e o Livro Didático}

Na educação escolar, o ensino e a aprendizagem da Matemática, em geral, ocorrem na sala de aula a partir de propostas e estratégias contidas no livro didático (LIMA, 2008). A influência desse recurso didático na escola não se restringe apenas a sua função didática como coadjuvante do educador na tarefa de sistematizar os conteúdos, mas pelos valores implícitos que podem reproduzir junto as suas propostas, contribuindo para uma determinada formação de sociedade e, sobretudo, do cidadão.

"[...] os textos didáticos presentes no livro podem influenciar o desenvolvimento de atitudes e de padrões de comportamento, contribuindo para a formação ética do aluno, preparando-o para o convívio equilibrado $e$ consciente das diversidades existentes em uma sociedade democrática" (BRASIL, 2003, p. 34).

Não há postura neutra, o livro didático para a área de Matemática é, também, responsável na educação escolar por uma determinada formação do sujeito, que pode estar relacionada aos propósitos para formar um cidadão crítico, participativo, reflexivo e responsável 
(LIMA, 2008). Assim, o livro didático pode corresponder a uma educação que permita, além de informar sobre direitos e deveres, fornecer instrumentos para questioná-los e vinculá-los na prática a lutar contra a exclusão e a marginalização, além de desenvolver valores tais como solidariedade, tolerância e respeito às diferenças.

As propostas dos PCN (BRASIL, 1998) ao relacionar a Matemática e a cidadania não se caracterizam apenas pelo reconhecimento e distribuição de direitos e deveres mais pela aquisição de determinadas habilidades no ensino. A depender da forma como são exploradas, podem estar voltadas a propiciar mudanças na sociedade ou apenas adaptar o cidadão ao modelo capitalista e competitivo desta, que como argumenta Canivez, "solicita determinadas competências para o exercício de uma função qualquer" (1991, p.68).

"[...] o modo como se dá o ensino e a aprendizagem, isto é, as opções didáticas, os métodos, a organização do tempo e do espaço que conformam a experiência educativa, ensinam valores, atitudes e práticas sociais. Por meio deles pode-se favorecer em maior ou em menor medida o desenvolvimento da autonomia e o aprendizado da cooperação e da participação social, fundamentais para que os alunos se percebam como cidadão" (BRASIL, 1998, p.24).

O conjunto dos PCN identifica que entre os recursos didáticos, o livro é um dos materiais de mais forte influência na prática de ensino brasileira. Especificamente, o volume referente aos temas transversais reconhece que os valores e regras são transmitidos por vários agentes, entre os quais, o livro didático (BRASIL, 1998, p.61).

Cabe ressaltar que o professor deve estar atento para que a sua autonomia pedagógica não seja comprometida quando usa o livro didático. É seu papel indispensável observar a adequação desse instrumento didático a sua prática pedagógica e ao seu aluno. "O livro didático é um recurso auxiliar no ensino e aprendizagem e não pode ocupar o lugar de destaque nesse processo" (BRASIL, 2010, p.13). É sempre desejável buscar complementá-lo, seja para ampliar suas informações e as atividades nele propostas, contornar suas deficiências, seja para adequá-lo ao grupo de alunos que o utilizam.

É possível investigar o conhecimento da Matemática presente nas atividades dos livros didáticos da área, refletindo de que forma alguns contextos evidenciam a sua contribuição para outros campos do saber. É consensual nos estudos da Educação Matemática que ensinar Matemática não se reduz à transmissão de informações sobre um saber acumulado. Portanto, o processo de ensino e de aprendizagem, nesse campo, envolve a construção de um leque variado de saberes e requer que se favoreça a participação ativa do aluno nessa construção.

O ensino deixa de ser centrado na transmissão de conteúdos e passa a ser orientado pela construção de conhecimentos; busca a interação entre os conhecimentos presentes em cada uma 
das áreas de ensino. Isso implica que cada conhecimento presente nas áreas pretende promover atitudes que sirvam para o exercício de intervenções e julgamentos práticos. Contribui, por exemplo, para o entendimento e a análise de problemas que envolvem o aluno em sua cidadania, em sua vida profissional, e para tomadas de decisões.

Para contribuir com uma formação mais crítica e construtiva, o livro de Matemática deve levar em conta diferentes práticas, enfoques, representações matemáticas. Da mesma forma, visar o equilíbrio entre os eixos de conteúdo, diversificar atividades e exercícios, valorizar os conhecimentos prévios do aluno, confrontar diferentes estratégias para a resolução de problemas, articular a Matemática com outras áreas de conhecimento e contextualizá-la histórica e socialmente (BRASIL, 2003). Tais expectativas em relação à Matemática no livro didático estão conectadas a uma concepção crítica de conhecimento voltada a uma Educação Matemática que contribui com uma formação mais criativa e construtiva de cidadania.

As atividades ou ações que estruturam o conhecimento matemático no ensino configuram-se como meios para uma prática mais consciente do cidadão quando proporciona o diálogo, a participação, o debate, o confronto de diferentes pontos de vista, a oportunidade de expressar opinião. Trata-se de incentivar a formação de um sujeito que saiba argumentar, respeitar o outro, interpretar a realidade, conhecer e discutir seus direitos e deveres. O livro didático de Matemática ao incorporar estas atividades pode corroborar para veicular uma prática de educação cidadã mais ativa.

As propostas dos PCN para a área da Matemática (BRASIL, 1997) e suas sugestões de recursos ou estratégias e dos temas transversais - se orientadas para as atividades e exercícios de forma crítica e presente no livro didático -, constituem-se, também, como meios que contribuem para veicular uma prática voltada para uma formação mais consciente e reflexiva do cidadão. $A$ possibilidade de o livro didático trazer ao ensino elementos da realidade para discussão que necessitem da utilização de ferramentas ou procedimentos matemáticos pode incentivar o cidadão a buscar compreender a si mesmo, refletir: pensar, questionar, julgar os problemas sociais, científicos e tecnológicos, tomar decisões e agir a ponto de se envolver hoje e futuramente em questões de valores pessoais e sociais. A título de exemplo, cita-se a leitura crítica ou a elaboração de um gráfico estatístico sobre um tema que envolva o Meio Ambiente ou a interpretação de uma fatura de energia elétrica.

"Algumas características dos temas transversais envolvem um aprender sobre a realidade, na realidade e da realidade, destinando-se também a um intervir na realidade para transformá-la. Outra de suas características é que abrem espaços para saberes extra-escolares. Na verdade, os temas transversais prestam-se de modo muito especial para levar à prática a concepção de formação integral da pessoa" (GARCIA apud VIZZOLLI et al, 2008, p.29). 
Assim, estabeleceu-se como objeto de investigação as temáticas presentes no livro didático relacionadas às propostas dos PCN para a área de Matemática, com enfoque no tema transversal Meio Ambiente.

Os educadores são os grandes articuladores para garantir a mobilização dos saberes, o desenvolvimento do processo e a realização dos trabalhos com os textos, as atividades e os exercícios no livro didático de Matemática, levantando questionamentos e discussões sobre o tema Meio Ambiente. Espera-se que os estudantes estabeleçam conexões entre o conhecimento adquirido e o pretendido em vista de uma contextualização, resolvendo situações-problemas condizentes com as suas condições cognitivas, emocionais e contextuais.

"Os materiais que se usa como recurso didático expressam valores $e$ concepções a respeito de seu objeto. A análise crítica desse material pode representar uma oportunidade para se desenvolver os valores $e$ as atitudes com as quais se pretende trabalhar" (BRASIL, 1998, p.37).

A maneira como se vê a importância de analisar a abordagem dos temas ambientais nas atividades, textos e exercícios do livro didático de Matemática para os anos finais do Ensino Fundamental desponta progressivamente como uma contribuição para o exercício de uma prática reflexiva em Educação Matemática.

\section{A Matemática, os Parâmetros Curriculares Nacionais e o Tema Transversal Meio Ambiente}

Segundo Groenwald e Silva (2001), a construção de um currículo matemático, considerando os temas de relevância social, confere ao mesmo uma perspectiva integradora e nesse sentido, sua organização se estabelece em torno de situações e problemas de interesse que permitam uma leitura, compreensão e interação da realidade social, cultural, política e natural. Um tema de relevância é sem dúvida a Educação Ambiental.

A forma como a Educação Ambiental foi incluída nos PCN, reconhece que a escola assume um papel fundamental na formação de cidadãos ativos e responsáveis, resgatando valores essenciais como a ética, fraternidade e respeito da vida em geral. Devido à abordagem holística e integradora da Educação Ambiental ela é trabalhada nos PCN, através da proposição do Meio Ambiente como tema transversal.

A legitimação dessa transversalidade implícita na temática ambiental representa um passo essencial para que a Educação Ambiental não continue a ser erroneamente pensada e reduzida na escola a mais uma disciplina do componente curricular pertencente à Biologia (RODRIGUES; RODRIGUES, 2001, p.34). Os problemas ambientais não se restringem apenas à proteção da vida, mas a qualidade da mesma. Desse modo, a distribuição desigual de renda, a 
injustiça social generalizada decorrente do modelo de desenvolvimento adotado, a corrida biológica, o individualismo crescente e os desafios da pluralidade cultural que hoje caracterizam o mundo globalizado também são encarados como ambientais.

A escolha do Meio Ambiente como um dos seis temas transversais foi definida de acordo com quatro critérios básicos: urgência social, questões de abrangência social, possibilidade de ensino (aprendizagem na educação fundamental), favorecimento da compreensão da realidade e da participação social (tomada de posicionamento frente as questões que interferem na vida coletiva) (BRASIL, 1998).

"A sobrevivência da Terra está ameaçada, tornando-se uma preocupação central e imediata. A situação atual exige medidas urgentes em todos os setores - científico, cultural, econômico e político -, além de uma maior sensibilização de toda a humanidade" (D’AMBROSIO, 1997, p. 49).

A questão ambiental é apresentada como um conjunto de temáticas que não dizem respeito apenas à proteção da vida no planeta, mas também à melhoria do Meio Ambiente e da qualidade de vida das diferentes comunidades, enfatizando o papel imprescindível da Educação e da participação popular na resolução de boa parte dos problemas responsáveis pela crise ambiental, reforçando a necessidade das práticas em Educação Ambiental de forma espontânea e consciente por parte daqueles que optam por realizá-las (RODRIGUES; RODRIGUES, 2001, p.35).

A apresentação do tema transversal Meio Ambiente nos PCN se dá em dois momentos bem definidos: no primeiro momento traça-se um histórico resumido das conferências e reuniões mundiais sobre o tema, onde a Educação Ambiental é apontada como elemento chave para promover novos pontos de vista e deflagrar novas posturas diante da problemática ambiental; no segundo momento discute-se a pedagogia da Educação Ambiental voltada para o Ensino Fundamental em termos de conteúdo, critérios de avaliação, práticas e orientações didáticas fundamentadas nas observações efetivadas na primeira parte.

Os destaques da segunda parte dos PCN para os temas transversais (BRASIL, 1998), referentes à seleção de conteúdos e orientações didáticas para o trabalho de Educação Ambiental, no Ensino Fundamental, ficam por conta dos objetivos a serem alcançados tais como:

"Conhecimento e compreensão integrada de noções básicas de meio ambiente; adoção de posturas sustentáveis em casa e na escola compatíveis com esta compreensão; observação e análise crítica de fatos e situações ambientais pertinentes ao tema; percepções de fenômenos de causa e efeito na natureza importante para compreensão do meio ambiente e seus diferentes ecossistemas; domínio de procedimentos de conservação e manejo de recursos naturais; percepção e valorização da diversidade natural e sociocultural e 
identificação pessoal como parte integrante do meio ambiente" (BRASIL, 1998, p 53-54).

De acordo com os PCN (BRASIL, 1998), os conteúdos relativos à temática ambiental estão divididos em três blocos que não são estanques, nem sequenciais, mas aglutinam conteúdos relativos aos diferentes aspectos que configuram a problemática ambiental. Eles possibilitam de maneira mais consistente esses determinantes dos vários ambientes, como eles se configuraram e como poderiam ser modificados. Os conteúdos relativos à temática ambiental são:

"Ciclos da natureza (enfocando o conjunto de inter-relações e fluxos presentes na natureza a partir de uma visão sistêmica); sociedade meio ambiente (voltado para o estudo das inter-relações entre grupos humanos e as atividades que desenvolvem num determinado espaço); manejo e conservação ambiental (de cunho mais prático, voltado para análise e incentivo de práticas que respeitem o meio ambiente e evitem desperdícios)" (BRASIL, 1998, p. 203).

É fundamental associar processos educativos formais às demais atividades de luta por qualidade de vida e sustentabilidade. São fundamentais projetos que articulem o trabalho escolar com o trabalho comunitário buscando conhecimento, a reflexão e ação concreta sobre o ambiente em que se vive (RODRIGUES; RODRIGUES, 2001, p.38).

A partir da inclusão da temática ambiental como tema transversal, os PCN ajudam no desenvolvimento da Educação Ambiental no âmbito formal, despertando o universo escolar para a importância da temática, sublinhando a necessidade de participação de todos os profissionais na escola, dando sua parcela de colaboração, sendo o convívio e a própria sala de aula, elementos decisivos para a aprendizagem de valores socioambientais. É preciso usar a criatividade, adaptar, buscar formas de melhor atender as demandas de cada realidade escolar (RODRIGUES; RODRIGUES, 2001).

A preservação do Meio Ambiente passa, indiscutivelmente, pela mudança de mentalidade e essa pode ser alcançada através da educação, trabalhando esses conceitos na escola, a qual é um polo divulgador e um dos responsáveis pelas mudanças de atitudes (GROENWALD; SILVA, 2001, p.166). Esse tema pode apresentar de acordo com o conteúdo matemático, a forma procedimental da coleta, organização e interpretação de dados estatísticos e outras situações que possam auxiliar a tomada de decisões sobre a prevenção do Meio Ambiente (como, a camada de ozônio, desmatamento, poluição). Segundo Lima, "com a quantificação, é permitido fazer as intervenções necessárias, por exemplo, reciclagem e aproveitamento de materiais. Além disso, (a) possibilita a interpretação dos resultados e levanta discussões acerca da preservação do Meio Ambiente; (b) estimula a pesquisa entre os alunos para além do livro didático" (LIMA, 2008, p.49).

Segundo os PCN, "a principal função do trabalho com o tema Meio Ambiente é contribuir para a formação de cidadãos conscientes, aptos a decidir e atuar na realidade socioambiental de 
um modo comprometido com a vida, com o bem-estar de cada um e da sociedade, local e global. Para isso é necessário que, mais do que informações e conceitos, a escola se proponha a trabalhar com a

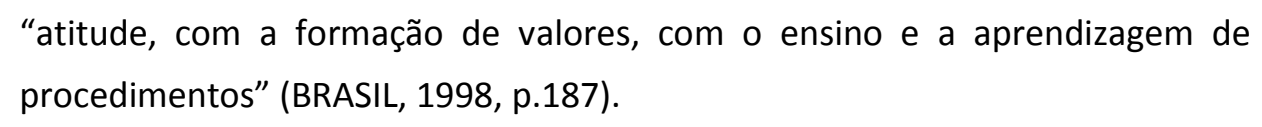

Com isso, é desejável que estejam presentes no livro didático, para o desenvolvimento curricular prescritos em conteúdos, propostas de atividades didáticas e exercícios que se relacionem e contribuam para o exercício da cidadania. No caso específico da Matemática, o texto dos PCN expõe que,

"[...] a matemática pode dar a sua contribuição à formação do cidadão ao desenvolver metodologias que enfatizam a construção de estratégias, a comprovação e a justificativa de resultados, a criatividade, a iniciativa pessoal, o trabalho coletivo e a autonomia advinda da confiança na própria capacidade para enfrentar problemas" (BRASIL, 1997, p. 16).

Mas, de fato, para relacionar a Matemática com a formação do cidadão na escola os livros didáticos devem apresentar estratégias, atividades e exercícios que possam contribuir para esse ensino, a fim de buscar aproximações com o que recomendam os PCN.

\section{Problema de Pesquisa}

O livro didático exerce uma grande influência sobre a educação escolar, como um instrumento que transmite ou veicula determinadas idéias e tendências da sociedade. Por isso, é pertinente investigar como essa ferramenta pedagógica utilizada para o ensino de Matemática contribui para a formação do cidadão com a perspectiva apresentada nos PCN.

A partir dessas considerações, surgiu a pergunta dessa investigação: o tema transversal Meio Ambiente está sendo abordada nos livros didáticos de Matemática dos anos finais do Ensino Fundamental, de acordo com as recomendações dos PCN e do PNLD?

\section{Objetivos da Investigação}

A pesquisa teve como objetivo geral investigar como o tema transversal Meio Ambiente está sendo abordado nos livros didáticos de Matemática dos anos finais do Ensino Fundamental, bem como, sua adequação aos PCN e ao PNLD.

A partir desse objetivo, foram estabelecidos os seguintes objetivos específicos: 
a) investigar o enfoque que o livro didático de Matemática dos anos finais do Ensino Fundamental dá ao tema transversal Meio Ambiente nos textos, atividades e exercícios;

b) verificar se as propostas dos PCN para o tema transversal Meio Ambiente estão presentes nos livros didáticos de Matemática adotados em duas escolas do município de Porto Alegre.

\section{Metodologia da Investigação}

Ao considerar o livro didático de Matemática para os anos finais do Ensino Fundamental, um instrumento importante no ambiente escolar, que contribui para incentivar um determinado ensino e a formação do cidadão, foi realizada a análise de duas coleções de livros didáticos acerca das atividades, textos e exercícios, identificando como o tema transversal Meio Ambiente é abordado.

Para realização desta investigação, foram selecionados quatro volumes, um de cada ano do Ensino Fundamental (6ำ 7으, 8으 e 9ㅇ) das coleções colocadas como primeira opção de escolha de duas Escolas Estaduais do município de Porto Alegre: Colégio Estadual de 1o e 2o Graus Dr. Glicério Alves e Escola Estadual de Ensino Fundamental Evarista Flores da Cunha.

Após as coleções terem sido definidas para a análise de conteúdo, foi realizado o planejamento e a execução de três etapas para a investigação.

A primeira etapa abordou a estrutura, a proposta das coleções selecionadas - para o ensino de Matemática e a abordagem do tema transversal Meio Ambiente. Nesta etapa a construção de quadros, referentes a estrutura e a proposta das obras selecionadas contribuiu para o início da coleta de dados, através deles identificou-se as seções que constituem o livrotexto de cada volume

A segunda etapa foi a coleta de dados nos volumes didáticos dos anos finais do Ensino Fundamental, das coleções selecionadas. A partir dos primeiros levantamentos obtidos, foi realizado um aprofundamento na coleta de dados, onde foi necessário explorar o conteúdo das coleções, analisando capítulo por capítulo, através de uma leitura detalhada das atividades, dos exercícios e dos textos, levando em consideração as recomendações dos PCN para a área de Matemática, assim como para o tema transversal Meio Ambiente. A coleta de dados permitiu organizar uma amostra através de quadros dessas atividades, exercícios e textos, incluindo os conteúdos (palavras-chave). Essas palavras formaram uma primeira referência, que possibilitou identificar as características e os critérios a serem utilizados para analisar a abordagem do tema transversal Meio Ambiente 
A terceira etapa constituiu-se em compreender os dados coletados, verificar os pressupostos da pesquisa e ampliar o conhecimento sobre o assunto pesquisado, articulando-o ao contexto sócio-cultural do qual faz parte.

Para melhor desenvolver os objetivos da análise de conteúdo, o problema que norteou a investigação foi inspirado na busca de subsídios para o ensino e aprendizagem de Matemática que de acordo com a proposta dos Parâmetros Curriculares Nacionais, possibilitassem aos alunos uma formação mais comprometida e responsável em torno desta disciplina.

\section{A interpretação e análise geral dos resultados para a coleção 1}

$\mathrm{Na}$ coleção 1 analisada, foram encontradas atividades que forneceram informações referentes às questões ambientais, mas envolveram a Matemática de forma reprodutiva, primando a técnica pela técnica, através de modelos e padrões a serem seguidos, não oportunizando o espaço para o diálogo e a discussão do tema, conforme ilustra a figura 1.

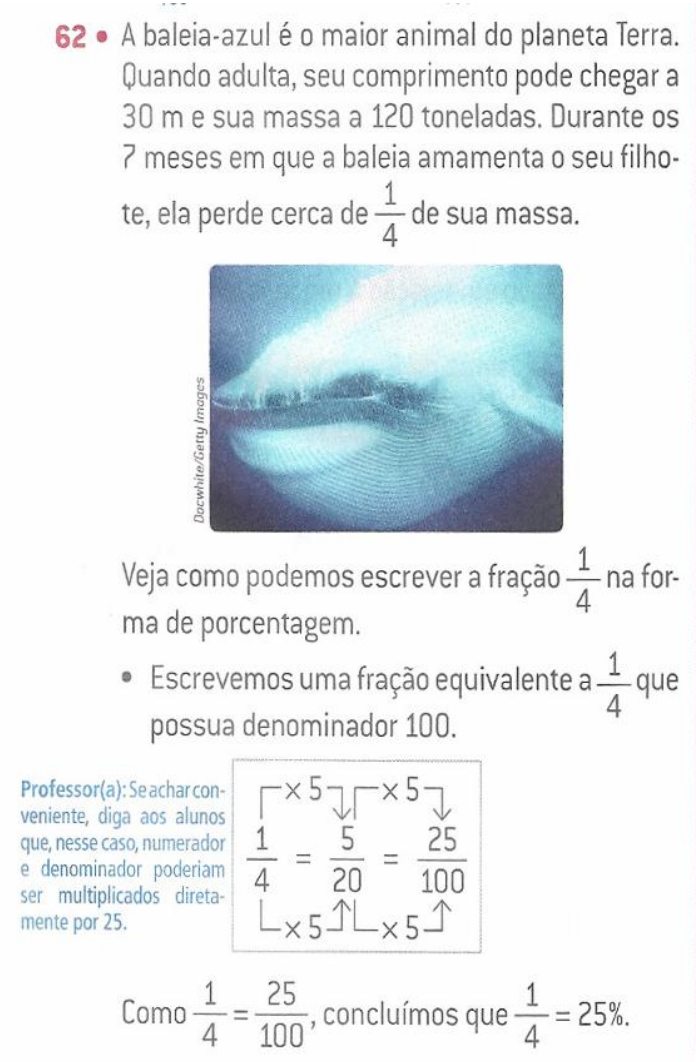

Agora, escreva no caderno as frações na forma de porcentagem.
a) $\frac{7}{10} 70 \%$
d) $\frac{1}{2} 50 \%$
g) $\frac{2}{5} 40 \%$
b) $\frac{3}{5} 60 \%$
e) $\frac{16}{25} 64 \%$
h) $\frac{6}{25} 24 \%$
c) $\frac{1}{5} 20 \%$
f) $\frac{?}{50} 14 \%$
i) $\frac{3}{20} 15 \%$

Figura 1 - Baleia-azul

(Fonte: RIBEIRO, 2010, p.131, v.1) 
No entanto, também se observou que a coleção 1 propõe atividades que apresentaram o conhecimento matemático como ferramenta conceitual (área, volume, perímetro, medidas, proporcionalidade) e procedimental (coleta de dados, tabelas, gráficos) para possibilitar a compreensão de temas ambientais.

$\mathrm{Na}$ atividade relacionada à reciclagem de materiais, conforme ilustra a figura 2, percebese a importância e os benefícios que essa prática traz à sociedade, verifica-se que a atividade também apresenta a Matemática conectada à realidade por meio da imagem e do texto que incentiva a aplicação ou utilização do conhecimento matemático como ferramenta, observando o espaço para a discussão dos possíveis resultados e diálogo.

\section{Divisão}
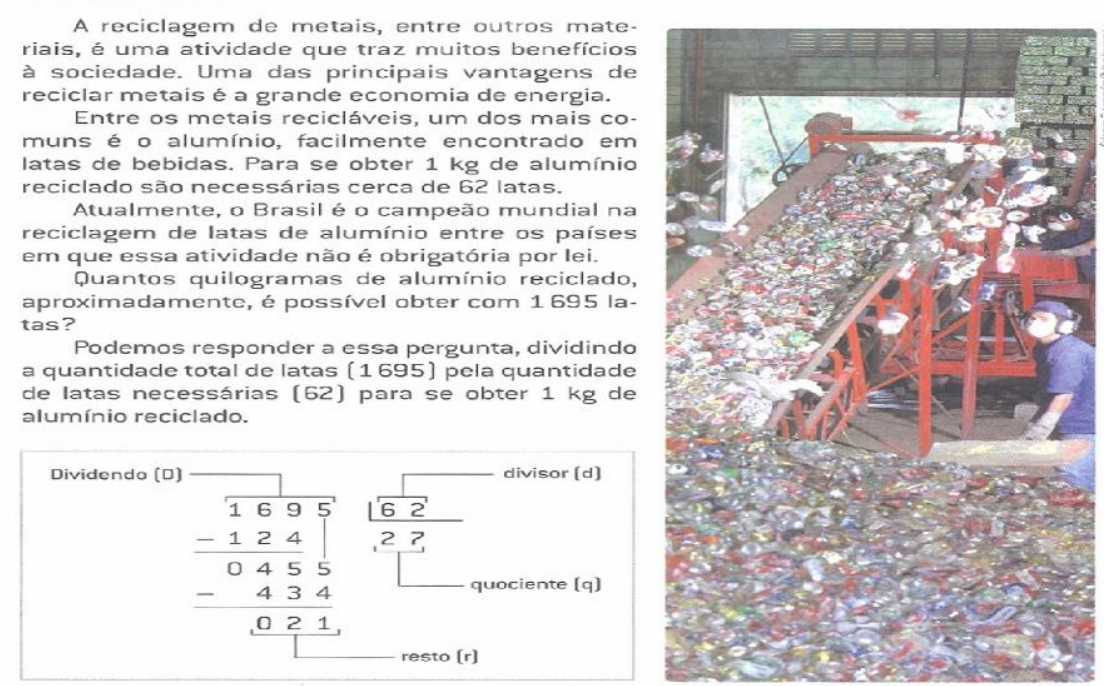

Portanto, com 1695 latas é possível obter, aproximadamente, 27 kg de alumínio reciclado.
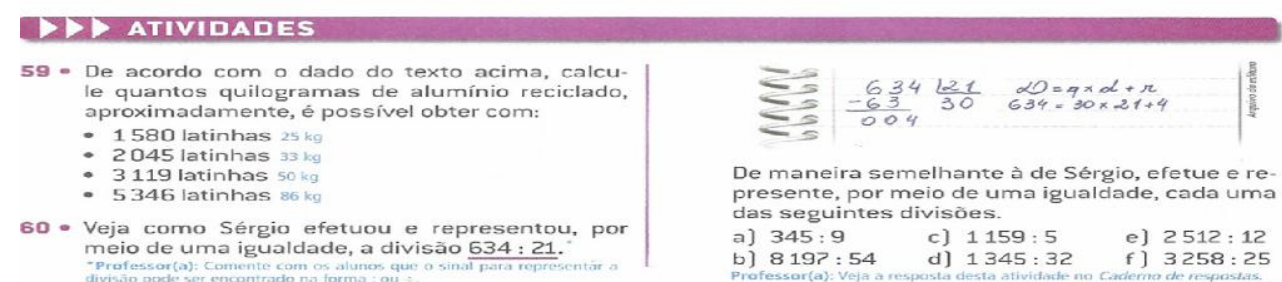

Figura 2 - Reciclagem de Materiais

(Fonte RIBEIRO, 2010, p.67, v.1)

Com base nesta atividade, o professor que está utilizando essa coleção poderia, ainda, propor aos alunos outras ações como calcular quantos quilogramas de alumínio reciclado, 
aproximadamente, é possível obter com as latas utilizadas pelos mesmos na escola, ou ainda, propor um projeto de investigação envolvendo o tema "Reciclagem de Resíduos".

Com relação aos textos analisados, na coleção 1 verifica-se que apresentam a Matemática conectada à realidade por meio de imagens, fotos, tabelas, gráficos que incentivam a aplicação ou utilização do conhecimento matemático como ferramenta, observando o espaço para a discussão dos possíveis resultados e diálogos, conforme ilustra a figura 3. Também se observa que os textos além de possibilitarem a interpretação dos resultados, permitem uma discussão acerca da preservação do Meio Ambiente.

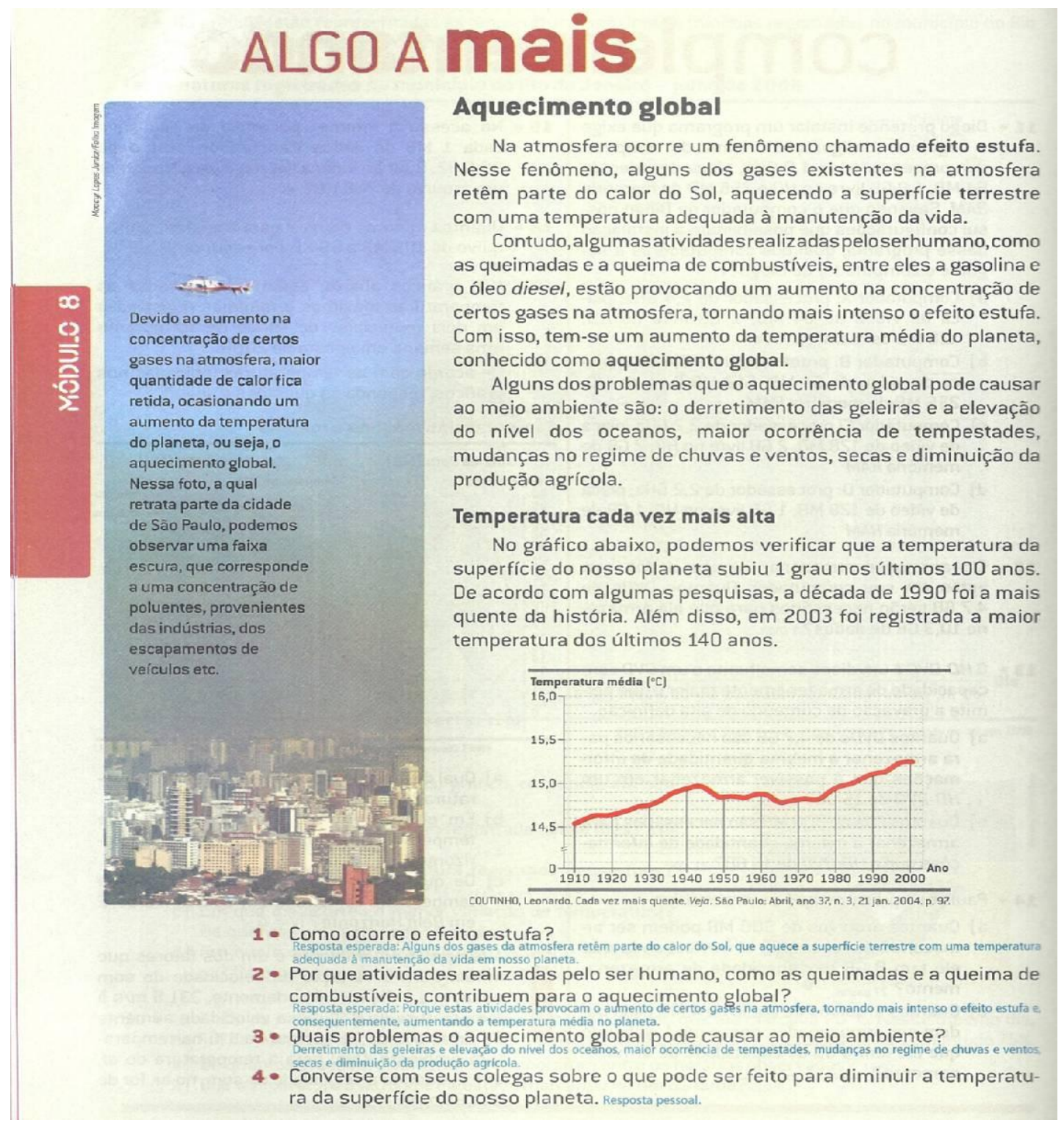

Figura 3 - Aquecimento global

(Fonte: RIBEIRO, 2010; p.220, v.2) 
Ao interpretar e analisar os dados obtidos na coleção 1 , verifica-se a presença do tema transversal Meio Ambiente em 213 atividades e em 71 textos desta coleção. A abordagem da temática é feita ao envolver e aplicar a Matemática a partir do contexto. O livro propõe atividades de discussão que podem levar o educando a adotar uma postura responsável na sociedade. Importante ressaltar que o livro didático é um recurso que o professor pode utilizar, porém é o docente o agente provocador e mediador desse processo.

\section{A interpretação e análise geral dos resultados para a coleção 2}

Na coleção 2, os textos abordam o tema transversal Meio Ambiente ao apresentar a Matemática conectada à realidade, envolvendo problemas sociais, científicos e tecnológicos, ao oportunizar diferentes estratégias ou procedimentos matemáticos para desenvolver o trabalho, propiciando aos alunos momentos de análise crítica das informações veiculadas pelos diferentes canais de comunicação (TV, jornais, revistas, vídeos, filmes, comerciais), como ilustra a figura 4.

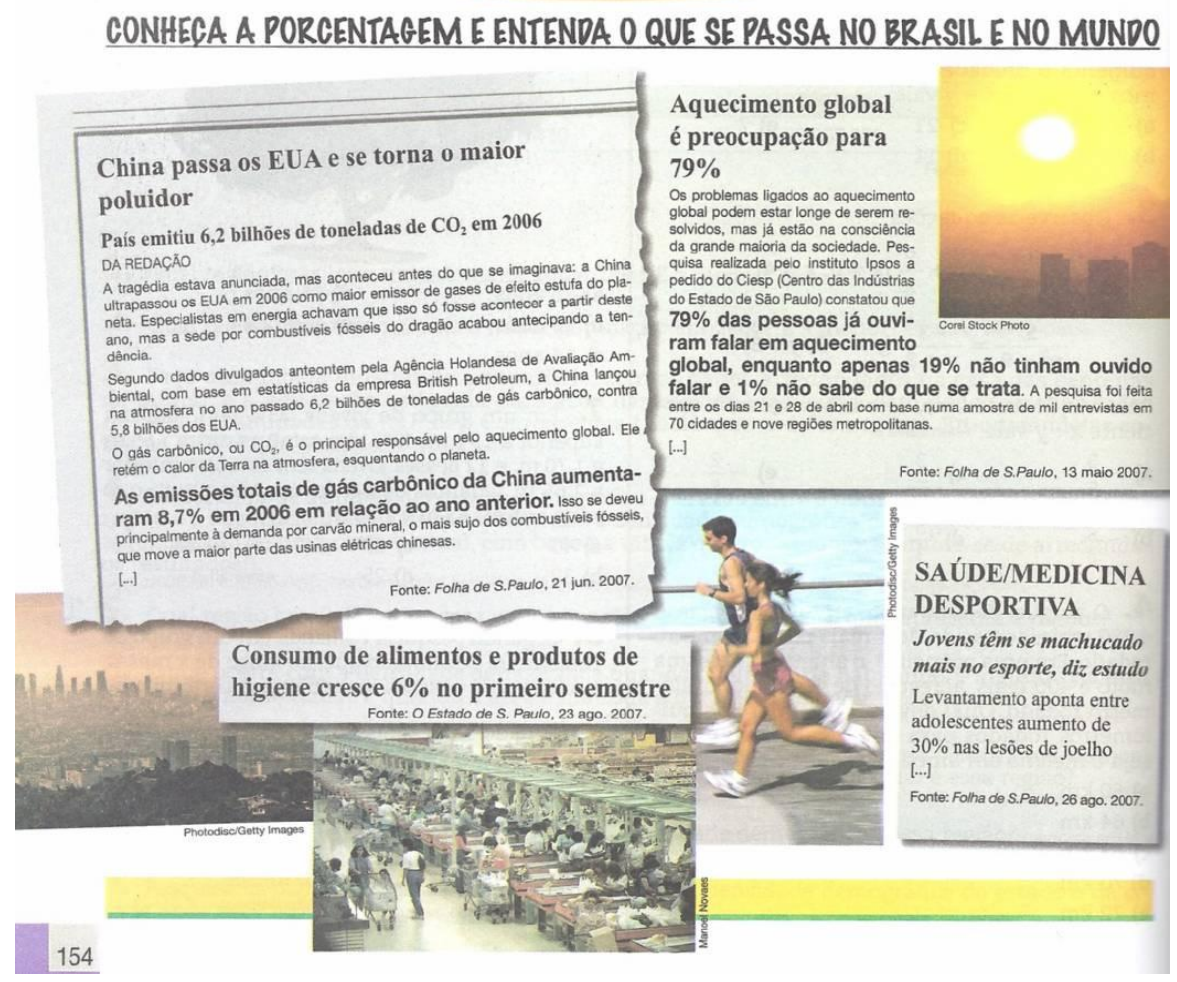

Figura 4: Conheça a porcentagem e entenda o que se passa no mundo

(Fonte: CASTRUCCI;GIOVANNI, 2009 p. 154, v.3) 
Também, se verificou a presença da temática Meio Ambiente nas atividades analisadas. Foram encontradas atividades que para abordar o tema transversal Meio Ambiente, utilizaram o conhecimento matemático como ferramenta procedimental (coleta de dados, tabelas, gráficos) e possibilitaram a utilização de recursos tecnológicos, como a calculadora para efetuar os cálculos propostos, como mostra a figura 5.

\section{IRTAANDO A MNFORAACGROO}

\section{INTERPRETANDO E CONSTRUINDO GRAFICOS}

1. Mais de 1 bilhão de pessoas poderão sofrer com a falta de água em um futuro próximo. As populações pobres do mundo serão as mais afetadas pelo aquecimento global em 2025 , dois terços da população viverăo areas onde as reservas O Brasil - privilegiado quanto ao volume de recursos hídricos - possui cerca de $12 \%$ de toda a água doce do planeta. Porém, a disponibilidade desses recursos não é uniforme no país.

Observando o gráfico ao lado, responda:

a) Que tipo de gráfico é esse? Gráfico de colunas triplas ou b) Indique a regiāo:

" com a maior superfície; Regiào Norte: 45,3\%

* com mais recursos hídricos; Região Norte: $68,5 \%$.

* com a segunda menor concentração de população.

c) Que região tem menor porcentagem de recursos hídricos do nosso país? Regiāo Nordeste: $3.3 \%$.

d) Em que região há maior concentração de popu-

lação? Regiầ Sudeste: $42,0 \%$

e) Pode-se dizer que quanto maior a superfície da região, maior é o número de habitantes? Justifique

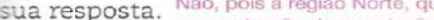

f) Quantos por cento da água doce do mundo estão na região Sudeste brasileira? Explique como você pensou para responder. O Brasil tem cerca de $12 \%$ de toda a água doce do planeta. A regiáo Sudeste tem $6 \%$ dos recursos hidricos

g) Pode-se dizer que a região que dispöe de mais recursos hídricos é a que possui a maior população? Não, pois a região Sudeste, que tem a maior concentração de populaçăo, é a segunda menor em recursos hídricos,

2. Observe este outro gráfico.

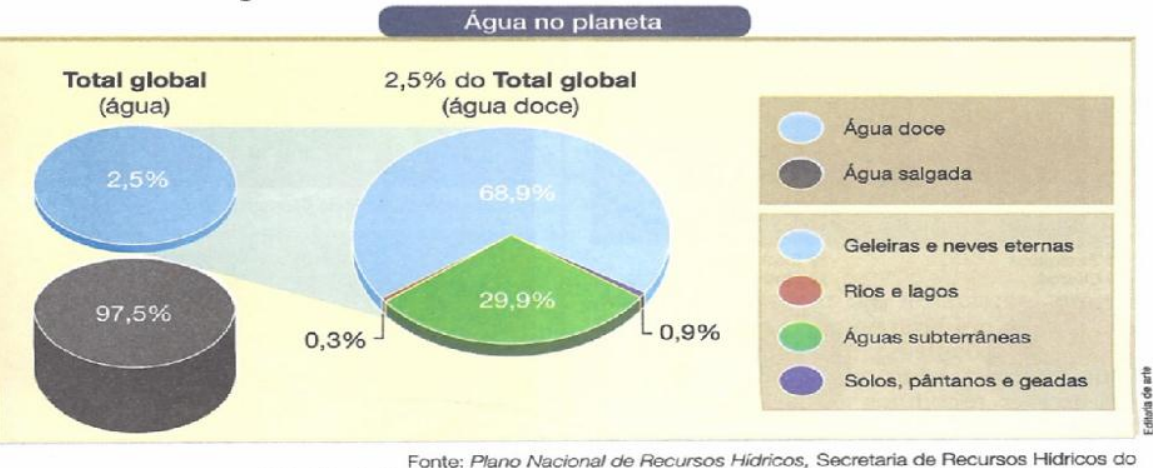

Ministério do Meio Ambiente, citado em: <wmw.idec.org.br/bibliotecas. Acesso em: 9 abr. 2007

Figura 5 - Interpretando e construindo gráficos

(Fonte: CASTRUCCI; GIOVANNI, 2009, p. 169, v.3) 
A figura 6 ilustra uma atividade em que os alunos têm a oportunidade de utilizarem o conhecimento sobre o Meio Ambiente para compreender a sua realidade e atuarem nela.

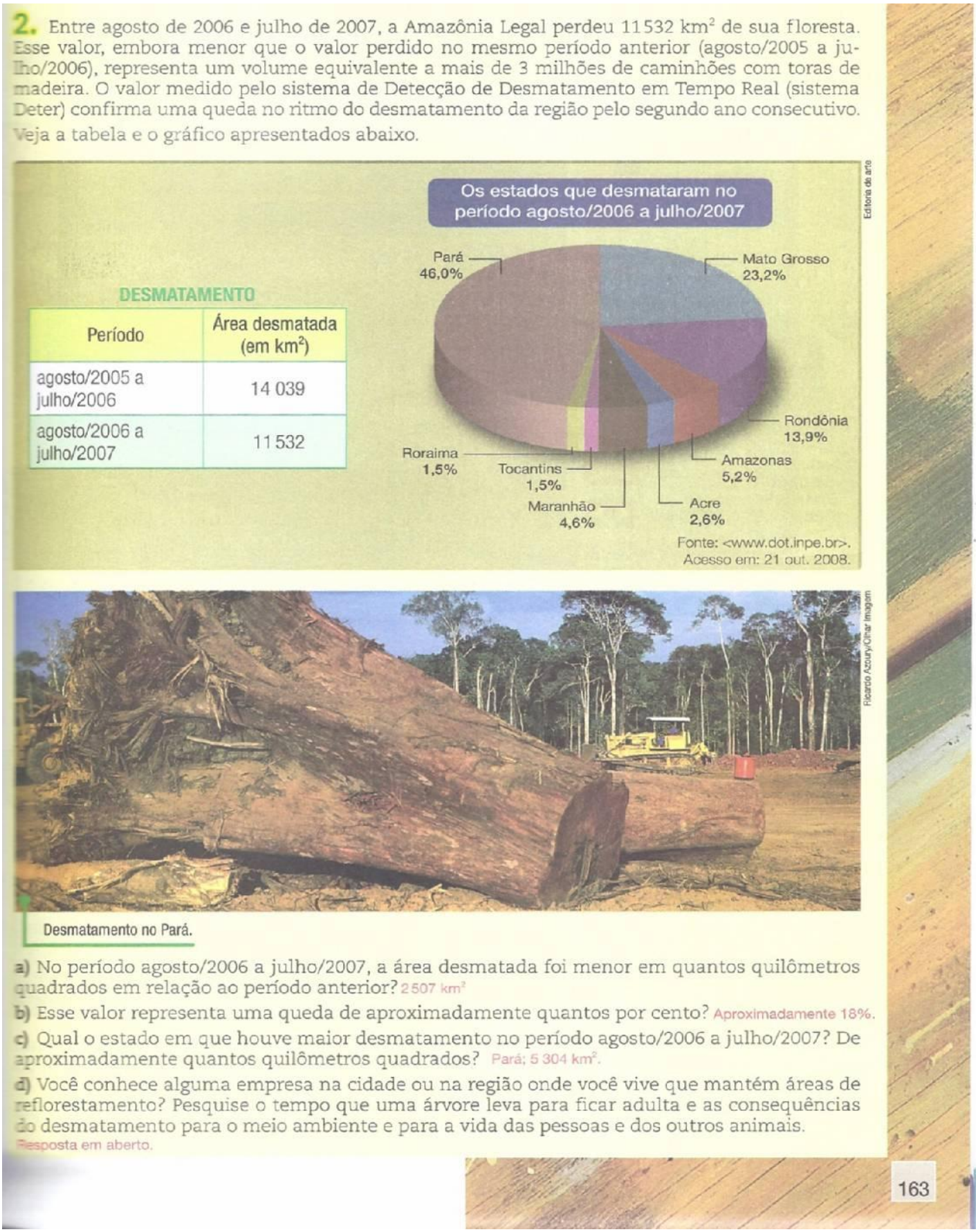

Figura 6- Desmatamento

(Fonte:CASTRUCCI; GIOVANNI, 2009, p.163, v.4) 
De acordo com os PCN (BRASIL, 1998), aspectos regionais de relevância devem ser discutidos com profundidade, pois assim, os alunos poderão, participando de momentos de trocas de conhecimentos e se envolvendo diretamente com aspectos da realidade local e com a construção coletiva de projetos assumirem o papel de participantes e co-responsáveis. Essa vivência possibilitará o afloramento de pontos de vistas coincidentes e divergentes, desvendando afinidades e permitindo o debate e o aprendizado do diálogo.

\section{Comparando as coleções}

Ao interpretar e analisar os dados obtidos se verificou a presença do tema transversal Meio Ambiente em ambas as coleções. A figura 7 ilustra o quadro com o número de atividades e textos encontrados em cada um dos volumes da coleção 1 e, a figura 8, apresenta o quadro com o número de exercícios e de textos encontrados em cada um dos volumes da coleção 2 .

\begin{tabular}{|c|c|c|}
\hline \multicolumn{3}{|c|}{ Coleção 1 } \\
\hline Volumes & $\begin{array}{c}\text { Número de Atividades que } \\
\text { abordam o tema transversal Meio } \\
\text { Ambiente }\end{array}$ & $\begin{array}{r}\text { Número de Textos que } \\
\text { abordam o tema transversal } \\
\text { Meio Ambiente }\end{array}$ \\
\hline Volume 1 & 67 & 16 \\
\hline Volume 2 & 69 & 25 \\
\hline Volume 3 & 41 & 11 \\
\hline Volume 4 & 36 & \multicolumn{1}{|c|}{} \\
\hline
\end{tabular}

Figura 7 - Quadro de Atividades e Textos da Coleção 1 


\begin{tabular}{|c|c|c|}
\hline \multicolumn{3}{|c|}{ Coleção 2 } \\
\hline Volumes & $\begin{array}{c}\text { Número de Atividades/ Exercícios } \\
\text { que abordam o tema transversal } \\
\text { Meio Ambiente }\end{array}$ & $\begin{array}{c}\text { Número de Textos que } \\
\text { abordam o tema transversal } \\
\text { Meio Ambiente }\end{array}$ \\
\hline Volume 1 & 48 & 05 \\
\hline Volume 2 & 37 & 03 \\
\hline Volume 3 & 20 & 09 \\
\hline Volume 4 & 20 & 07 \\
\hline
\end{tabular}

Figura 8 - Quadro de Atividades e Textos da Coleção 2

Analisando o conjunto das informações constata-se que os volumes que constituem a coleção 1 apresentam um número maior de atividades e textos que abordam o tema transversal Meio Ambiente.

\section{Conclusão}

De acordo com os dados coletados foi possível identificar nos exercícios, nos textos e nas atividades a presença do tema transversal Meio Ambiente. Porém, as atividades e os exercícios, poderiam explorar mais a concepção crítica e contextualizadora do conhecimento matemático, enfatizando o trabalho com atitudes, com a formação de valores, com o ensino e a aprendizagem de procedimentos que contribuam para a formação de cidadãos conscientes, aptos a decidir e atuar na realidade socioambiental de um modo comprometido com a vida, com o bem-estar de cada um e da sociedade, local e global.

Nesse sentido, segundo os PCN (BRASIL, 1998), o ensino deve ser organizado de forma a proporcionar oportunidades para que os alunos possam utilizar o conhecimento sobre Meio Ambiente para compreender a sua realidade e atuar nela, por meio do exercício da participação em diferentes instâncias: nas atividades dentro da própria escola e nos movimentos da comunidade. É essencial resgatar os vínculos individuais e coletivos com o espaço em que os alunos vivem para que se construam essas iniciativas, essa mobilização e envolvimento para solucionar problemas.

Observou-se que a presença do critério referente à concepção crítica e contextualizadora do conhecimento matemático, a qual envolve prover os sujeitos com ferramentas conceituais, procedimentos e atitudes que os tornem aptos a participar de forma responsável e crítica na sociedade, foi mais significativa nos textos encontrados em ambas as coleções. 
Constatou-se que o trabalho com o conteúdo de Matemática por intermédio de atividades, textos e exercícios no livro didático nas quais se apliquem os pressupostos da concepção crítica e contextualizadora do conhecimento matemático constituiu-se um campo fértil em possibilidades para o processo de ensino e aprendizagem. Por estarem em sintonia com a proposta sugerida nos PCN, tais possibilidades poderão favorecer os alunos a desenvolver seu senso crítico, ao propor que estes tomem decisões diante das situações que o contexto científicotecnológico lhes apresentar.

$\mathrm{Na}$ coleção 2 também foram analisadas as propostas de trabalho com projetos pedagógicos interdisciplinares, localizados no final de cada volume. A temática Meio Ambiente poderia ter sido enfatizada, conforme nossas reflexões, em pelo menos um dos projetos pedagógicos interdisciplinares dos volumes da coleção, pois segundo os PCN (BRASIL, 1998),

"A organização dos conteúdos em torno de projetos como forma de desenvolver atividades de ensino e aprendizagem, favorece a compreensão da multiplicidade de aspectos que compõe a realidade, uma vez que permite a articulação de contribuições de diversos campos de conhecimento. Esse tipo de organização permite que se dê relevância às questões dos temas transversais, pois os projetos podem se desenvolver em torno deles e serem direcionados para metas objetivas, com a produção de algo que sirva como instrumento de intervenção nas situações reais".

Cabe aos educadores através das atividades, dos exercícios e dos textos do livro didático de Matemática, promover oportunidades para que os alunos se envolvam em debates e discussões que possam articular a Matemática com o desenvolvimento sócio-cultural e científicotecnológico, tendo como objetivo melhorar a qualidade de vida e modificar atitudes e práticas pessoais adotando a ética e o respeito para preservar o Meio Ambiente e viver em sociedade.

\section{Referências}

Brasil. Secretaria de Educação Fundamental. Parâmetros curriculares nacionais: matemática. Brasília: MEC/SEF, 1997.

Brasil. Secretaria de Educação Fundamental. Parâmetros curriculares nacionais: terceiro e quarto ciclos: apresentação dos temas transversais. Brasília: MEC/SEF, 1998.

Brasil. Ministério da Educação. Fundo Nacional de Desenvolvimento da Educação. Guia de livros didáticos: 1a a 4a séries: PNDL 2004-2006. Brasília: MEC/SEF, 2003.

Brasil. Ministério da Educação. Fundo Nacional de Desenvolvimento da Educação. Guia de livros didáticos: PNDL 2011: Matemática. Brasília: MEC/SEF, 2010. 
Castrucci, Benedicto; Giovanni José Ruy. A Conquista da Matemática. São Paulo: FDT, 2009 (Coleção A Conquista da Matemática v. 1, 2, 3 e 4).

Canivez, Patrice. Educar o cidadão? Ensaios e textos. Campinas: Papirus, 1991.

D’Ambrósio, Ubiratan. Transdisciplinariedade. São Paulo: Palas Athena, 1997

Filippsen, Rosana Maria Jardim; Groenwald, Claudia Lisete Oliveira. Educação matemática e educação ambiental: educando para o desenvolvimento sustentável. Canoas, 2003. Disponível em: <http://www.liberato.com.br/upload/arquivos/0131010716351516.pdf > Acesso em 07 de set. de 2010

Groenwald, Claudia Lisete Oliveira; Silva, Carmen Kaiber da. Integrando a matemática ao tema educação ambiental. Paradigma. Maracay. v.22, n.2, p.151-170, dezembro 2001.

Lima, Claudine Assumpção. Aproximações entre ciência-tecnologia-sociedade e os temas transversais no livro didático de matemática do ensino fundamental de 5a A 8 a séries. 2008.200p. Dissertação (Mestrado em Educação

Científica e Tecnológica), Faculdade em Educação, Universidade Federal de Santa Catarina. Florianópolis, 2008. Disponível em:

< http://www.ppgect.ufsc.br/dis/53/dissert.pdf> Acesso em 19 jun de 2010

Ribeiro, Jackson. Projeto Radix. São Paulo Scipione, 2010. (Coleção Projeto Radix v. 1, 2, 3 e 4).

Rodrigues, Ana Paula da Mota; Rodrigues, Milena Goulart Souza. A educação ambiental e os Parâmetros Curriculares Nacionais: um olhar sobre a transversalidade da questão. 2001. 54 p. Projeto final de curso apresentada como parte dos requisitos necessários para obtenção do Certificado de Formação Profissional em Ciências Ambientais, Universidade Federal do Rio de Janeiro. Rio de Janeiro, 2001. Disponível em:

<http://pulsar.org.br/portal/s/o/documentos/apost.doc. > Acesso em 6 jul de 2010

Vizolli, Idemar. et al. Operações de multiplicação:abordagens presentes em livros de 5 a série.Educação Matemática em Revista, Canoas: ULBRA, v.1, n. 1, p.27-37, set. 2008.

Karine Machado Fraga de Melo. Mestranda do Programa de Pós-Graduação em Ensino de Ciências e Matemática-ULBRA.k arinemfm@ig.com.br

Claudia Lisete Oliveira Groenwald. Doutora em Ciências da Educação. Professora do Programa de Pós-Graduação em Ensino de Ciências e Matemática - ULBRA-RGS claudiag@ulbra.br 